\title{
Discrimination of healthy and glaucomatous eyes based on the ocular pulse amplitude: A diagnostic case-control study
}

Robert, Y C A ; Wild, A ; Kessels, A G ; Backes, W H ; Zollinger, A ; Bachmann, L M

\begin{abstract}
By measuring the ocular pulse amplitude (OPA), the dynamic contour tonometer (DCT) assesses intraocular pressure (IOP). Hypothesizing that OPA is characteristic for the IOP when considered with the systemic arterial blood pressure, we assumed the ratio of ocular and arterial pulsation amplitudes is larger in glaucoma patients. Bi-ocular DCT-OPA assessment was synchronized with arterial pulsations using Finapres ${ }^{\circledR}$ technology, thereby enabling blood pressure determination for each corresponding IOP value every $0.01 \mathrm{~s}$ for $12 \mathrm{~s}$. Based on measurements and calculations in 10 healthy subjects and 11 glaucoma patients, we conclude that the ratio of the OPA and blood pressure variances is a strong glaucoma diagnostic indicator, thereby justifying further investigation.
\end{abstract}

DOI: https://doi.org/10.1159/000334616

Posted at the Zurich Open Repository and Archive, University of Zurich

ZORA URL: https://doi.org/10.5167/uzh-61157

Journal Article

Published Version

Originally published at:

Robert, Y C A; Wild, A; Kessels, A G; Backes, W H; Zollinger, A; Bachmann, L M (2012). Discrimination of healthy and glaucomatous eyes based on the ocular pulse amplitude: A diagnostic case-control study. Ophthalmic Research, 48(1):1-5.

DOI: https://doi.org/10.1159/000334616 


\title{
Discrimination of Healthy and Glaucomatous Eyes Based on the Ocular Pulse Amplitude: A Diagnostic Case-Control Study
}

\author{
Yves C.A. Robert ${ }^{a}$ Andreas Wild ${ }^{d}$ Alfons G. Kessels ${ }^{f}$ Walter H. Backes ${ }^{e}$ \\ Andreas Zollinger $^{b}$ Lucas M. Bachmann ${ }^{c}$ \\ ${ }^{a}$ Eye Department and ${ }^{b}$ Department of Anesthesiology and Intensive Care Medicine, Triemli Hospital, \\ ${ }^{\mathrm{c}}$ Horten Centre, University of Zurich, Zurich, and ${ }^{\mathrm{d}}$ Eye Clinic Pallas, Olten, Switzerland; Departments of \\ ${ }^{\mathrm{e}}$ Radiology and ${ }^{\mathrm{f} C l i n i c a l}$ Epidemiology and Medical Technology Assessment, Maastricht University Medical Centre, \\ Maastricht, The Netherlands
}

\section{Key Words}

Glaucoma $\cdot$ Ocular pulse amplitude $\cdot$ Dynamic contour tonometer · Finapres ${ }^{\circledR}$

\begin{abstract}
By measuring the ocular pulse amplitude (OPA), the dynamic contour tonometer (DCT) assesses intraocular pressure (IOP). Hypothesizing that OPA is characteristic for the IOP when considered with the systemic arterial blood pressure, we assumed the ratio of ocular and arterial pulsation amplitudes is larger in glaucoma patients. Bi-ocular DCT-OPA assessment was synchronized with arterial pulsations using $\mathrm{Fi}$ napres ${ }^{\circledR}$ technology, thereby enabling blood pressure determination for each corresponding IOP value every $0.01 \mathrm{~s}$ for $12 \mathrm{~s}$. Based on measurements and calculations in 10 healthy subjects and 11 glaucoma patients, we conclude that the ratio of the OPA and blood pressure variances is a strong glaucoma diagnostic indicator, thereby justifying further investigation.

Copyright $\odot 2011$ S. Karger AG, Basel
\end{abstract}

\section{Introduction}

When glaucoma is associated with anatomic anomalies in the anterior segment, diagnosis and follow-up of the disease primarily rely on tonometry and functional tests. However, most types of glaucomas, i.e. primary open-angle glaucoma and low-tension glaucoma, do not show any apparent anatomic landmark in the anterior segment and often present normal tonometric values. This makes discrimination difficult.

The ocular pulse amplitude (OPA) is a physiological parameter [1-3]. It originates from the heartbeat and travels as a pressure wave along the arterial branches to the ciliary arteries and the choroid $[2,3]$. As it enters the eye, the wave demonstrates a purely arterial behavior. It eventually reaches the sclera/cornea and the aqueous humor. In the chamber angle, the aqueous humor outflow through the trabeculum attenuates the pulse wave. This damping effect depends on the outflow resistance [4]. Consequently, OPA measurements should be able to detect differences in trabecular outflow characteristics between normal and glaucomatous eyes. 
Fig. 1. Sample of Fourier analysis for finger and ocular pulsation of one patient.

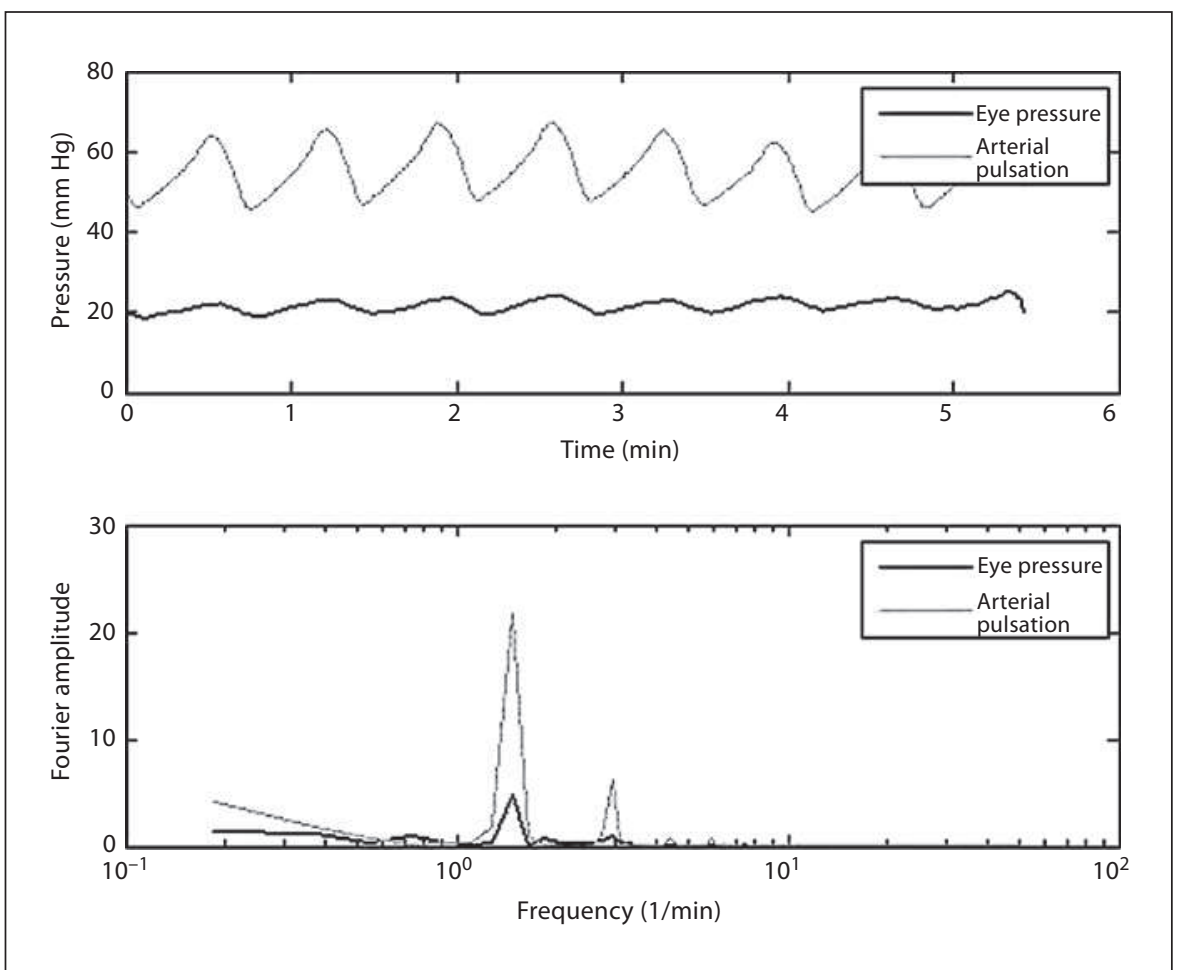

Dynamic contour tonometry (DCT) measures the intraocular pressure (IOP) and its variation directly and without deformation of the eye, and thereby provides a raw signal of the pressure curve [1]. Any alteration from a pure arterial signal can be seen by comparison with a similar peripheral arterial pulse wave, e.g. at the fingertip [5]. We therefore hypothesized that the increased outflow resistance in glaucoma patients modifies ocular pulsations, as measured by DCT. Consequently, we presumed that the ratio of the ocular pulsation amplitude to the arterial pulsation amplitude would be larger in healthy subjects than in glaucoma patients and thus investigated the diagnostic performance of this ratio in detecting glaucoma.

\section{Material and Methods}

\section{Participants}

The Ethics Committee of the Stadtspital Triemli approved this study, which followed strictly the tenets of the Declaration of Helsinki. All participants provided oral and written informed consent. We recruited a convenience sample of 11 glaucoma patients attending the Triemli outpatient eye clinic and 10 healthy subjects recruited from house staff. All participants underwent measurements in a standardized fashion. Two weeks prior to the test, all ocular medication in the glaucoma group was stopped.
Slitlamp examination of the anterior and posterior segment was done routinely, without touching the eye. In order to avoid artifacts, the chamber angle of the patients was not examined during study measurements. In previous examinations, the visual field had been evaluated using the Octopus 901, Program G1 or similar. Interpretation of the fields adhered to the guidelines of the European Glaucoma Society [6].

\section{Tonometry}

First, Goldmann applanation tonometry [7] was performed with 3 measurements for each eye, the right eye first, and the mean was taken; afterwards, the DCT was measured. Goldmann applanation tonometry measurement served as an internal quality control. The measurement was repeated, if necessary, and considered valid if a pulse curve was registered over a period of at least $12 \mathrm{~s}$ and if the value corresponded to the Goldmann applanation tonometry value.

\section{Arterial Pulse Measurement}

Before the IOP measurement and with the patient sitting at the slitlamp, the third finger of the left hand was armed with the cuff of a noninvasive, beat-to-beat cardiovascular Finometers PRO monitor (BMEYE BV, Amsterdam, the Netherlands). The device measures the arterial blood pressure continuously. The method is based on the dynamic pulsatile unloading of the finger arterial walls. The width of an artery under the cuff wrapped around a finger is kept constant ('clamped') at a certain diameter, in spite of the changes in arterial pressure during each heart beat. Changes in diameter, i.e. during systole, are detected immediately by an infrared photo-plethysmographic sensor built into the finger cuff, 
Table 1. Distribution of gender, age, IOP based on Goldmann applanation tonometry, mean systemic blood pressure, and OPA of patients and controls

\begin{tabular}{llll}
\hline & Glaucoma group & Controls & p value \\
\hline Number of males & $6(55 \%)$ & 0 & $0.01^{1}$ \\
Mean age \pm SD, years & $67.1 \pm 12.0$ & $43.5 \pm 11.2$ & $<0.001^{2}$ \\
IOP, mm Hg & $18.8 \pm 3.9$ & $18.3 \pm 2.3$ & 0.75 \\
$\quad$ Median & 18.9 & 18.6 & \\
$\quad$ Interquartile range & $15.2-21.8$ & $16.4-20.0$ & 0.20 \\
System pressure, mm Hg & $94.8 \pm 30.0$ & $81.6 \pm 25.4$ & \\
$\quad$ Median & 92.3 & 81.5 & \\
$\quad$ Interquartile range & $69.8-111.8$ & $68.5-98.5$ & \\
OPA ${ }^{3}$, mm Hg & 3.67 & 2.99 & - \\
$\quad$ Range & $2.57-4.68$ & $1.84-4.51$ & - \\
Comorbidities & see table 2 & none & \\
Medications & see table 2 & none & \\
\hline
\end{tabular}

${ }^{1}$ Fisher's exact test. ${ }^{2}$ Wilcoxon rank-sum (Mann-Whitney) test. ${ }^{3} 1$ st component of the Fourier analysis.

and a rapid pressure servo controller increases cuff pressure to prevent diameter change. Peak systolic pressure is reached when the amplitude of the pulsations in the plethysmogram is largest [5]. Sampling frequency was $100 \mathrm{~Hz}$. This system was then connected to the monitor. An electronic trigger mechanism, especially designed for our purpose, was attached to the tonometer ensuring the temporal attribution of the signals from the tonometer and the monitor. This guaranteed an identical time scale for the two signals. A simultaneous measurement time of at least $12 \mathrm{~s}$ was required in order to consider a measurement valid.

\section{Statistical Analysis}

We investigated the diagnostic performance using two parameters. First, we used the standard deviation of each of the ocular and the arterial pulse amplitude signals as an approximation for the amplitudes of the ocular and arterial pressure, which is easily determined by standard software. With these two standard deviations, the ratio was calculated as a diagnostic parameter. Second, for each of the individual signals (ocular and arterial pressure), we performed a fast Fourier transform Fourier spectral analysis [8]. From these, we calculated the ratio of the amplitudes of the first component (fig. 1). The diagnostic performance of both ratios was investigated with receiver operating characteristic curves and areas under the curves $[9,10]$.

\section{Results}

There were 6 (55\%) males in the glaucoma group, while there were only females in the control group. The mean age of the glaucoma patients was 67.1 years (SD 12.0) and 43.5 years (SD 11.2) in the controls. The mean IOP [18.8 $\mathrm{mm} \mathrm{Hg}$ (SD 3.9) vs. $18.3 \mathrm{~mm} \mathrm{Hg}$ (SD 2.3)] and the mean systemic arterial pressure [94.8 $\mathrm{mm} \mathrm{Hg}$ (SD 30.0) vs. 81.6 $\mathrm{mm} \mathrm{Hg}$ (SD 25.4)] were quite similar. Five out of 11 glaucoma patients had systemic hypertension and were taking antihypertensive drugs at the time of measurements. Details are given in tables 1 and 2 .

In total, we obtained 6,112 measurements of ocular pressure and systemic blood pressure of glaucoma patients (between 99 and 1,141 measurements per patient) and 4,994 measurements (between 404 and 648 measurements per subject) of controls.

Figure 2 displays a box plot distribution of standard deviations of the pressure/pulse ratio derived for glaucoma patients and healthy controls. As shown in figure 3, the discriminative capacity, as quantified with the area under the receiver operating characteristic curve, derived from the ratio of standard deviations of IOP and systemic pressure, was as high as 0.81 (95\% CI 0.58-1.00). The diagnostic performance of the first Fourier Spectral Analysis component of that ratio was even higher at 0.85 (95\% CI 0.66-1.00).

\section{Discussion}

Discrimination of early primary open-angle glaucoma from normal subjects is difficult due to long-term fluctuation in psychophysical testing [11], and due to the nonlinear character of progression in the anatomic structures, e.g. excavation in optic nerve head [12].

Earlier studies, using the pulsatile blood flow system according to Langham, tried to discriminate between healthy and glaucomatous [13] eyes. These data cannot be 
Table 2. Ophthalmologic history, comorbidity and comedication

\begin{tabular}{|c|c|c|c|c|}
\hline Sex & $\begin{array}{l}\text { Age } \\
\text { years }\end{array}$ & Ophthalmologic history & Other illnesses & $\begin{array}{l}\text { Medication (local eye medication stopped } \\
2 \text { weeks prior to study) }\end{array}$ \\
\hline Male & 75 & bilateral NTG and high myopia & $\begin{array}{l}\text { polymyalgia rheumatica, systemic } \\
\text { hypertension, diabetes, coronary } \\
\text { artery disease }\end{array}$ & $\begin{array}{l}\text { bimatoprostum, candesartanum, aspirin, } \\
\text { gliclazidum, metformin, prednisone }\end{array}$ \\
\hline Female & 83 & advanced bilateral POAG & systemic hypertension & $\begin{array}{l}\text { dorzolamide + timolol, latanoprostum, } \\
\text { lisinopril, binil }\end{array}$ \\
\hline Male & 71 & bilateral NTG & systemic hypertension & latanoprostum, lisinopril, aspirin \\
\hline Female & 59 & bilateral NTG & systemic hypertension & $\begin{array}{l}\text { dorzolamide + timolol, latanoprostum, } \\
\text { candesartanum }\end{array}$ \\
\hline Male & 46 & bilateral POAG, status after TE OS & none & timoptol, bimatoprostum \\
\hline Male & 61 & bilateral POAG & none & dorzolamide + timolol, bimatoprostum \\
\hline Female & 69 & bilateral pigmentary glaucoma & systemic hypertension & latanoprostum, candesartanum, carvedilol \\
\hline Male & 60 & traumatic glaucoma & none & timoptol, latanoprostum \\
\hline Female & 82 & advanced bilateral POAG & arthritis & brinzolamide, travatan \\
\hline Female & 78 & bilateral exfoliation glaucoma & none & timoptol, latanoprostum \\
\hline Male & 54 & bilateral POAG & none & latanoprostum \\
\hline
\end{tabular}

$\mathrm{NTG}=$ Normal-tension glaucoma $\mathrm{POAG}=$ primary open-angle glaucoma $; \mathrm{TE}=$ trabeculectomy .

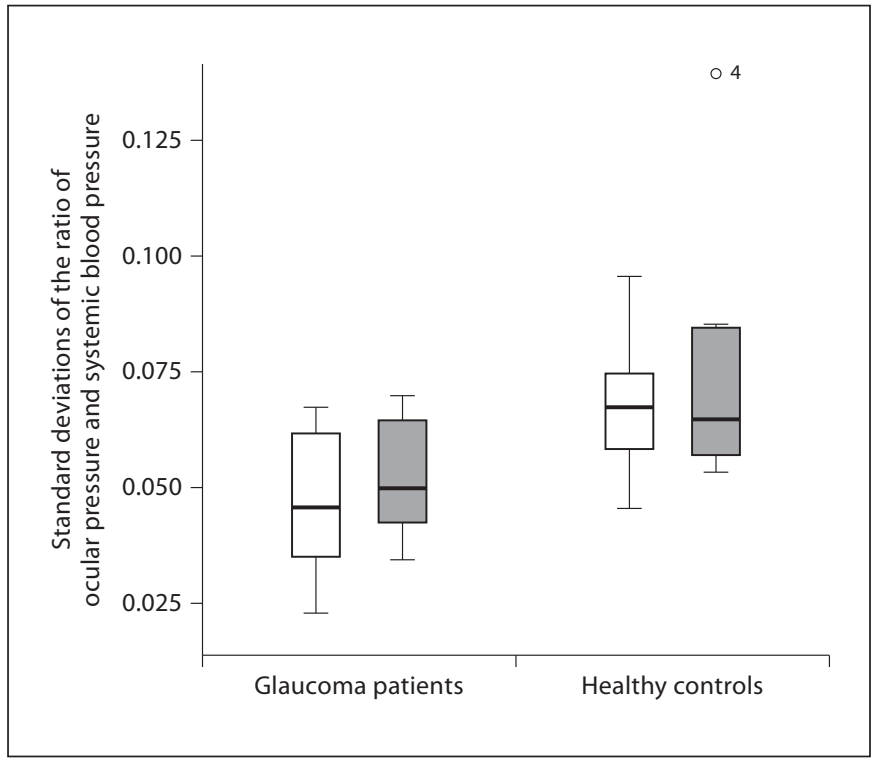

Fig. 2. Box plot distribution of standard deviations of the pressure/pulse ratio for glaucoma patients and healthy controls.

compared, since the ocular blood flow system is based on applanation of the cornea and thus influenced by, for example, ocular rigidity and axial length. More recent data using DCT reveal a difference based solely on the OPA [14].

Measuring the IOP and the OPA alone in our study does not reveal the difference between normal subjects

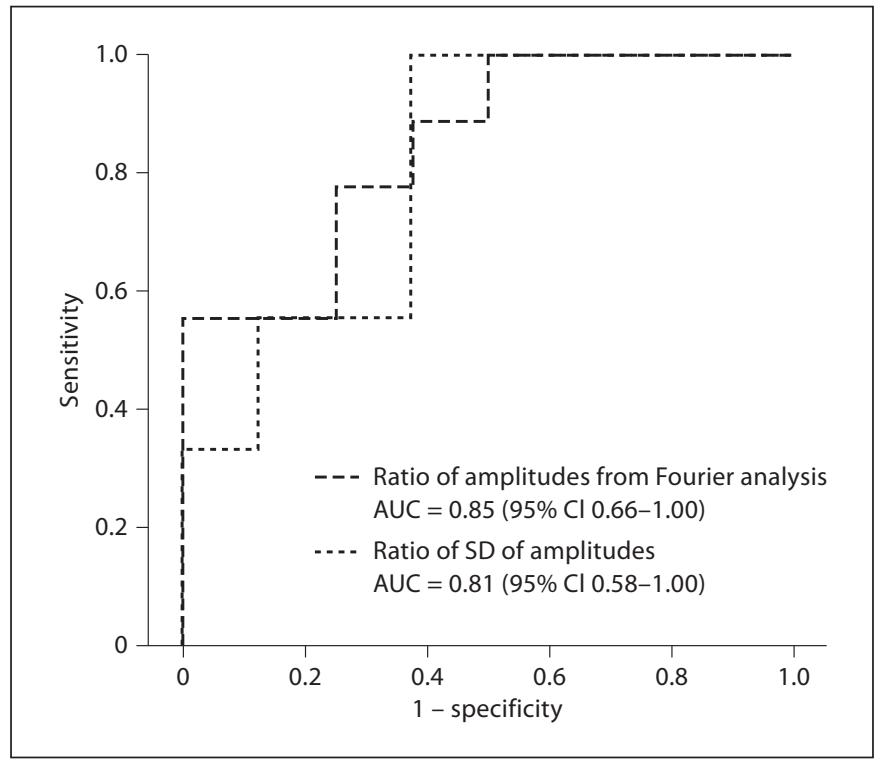

Fig. 3. The discriminative capacity and diagnostic performance of the OPA.

and glaucoma patients (table 1). However, when looking at the OPA in relation to the arterial pulsation, the difference becomes apparent. In our set-up, pulsation at the fingertip and at the eye was synchronized. This enabled us to compute the two waves, beat-to-beat, with each other. We have been able to show that the OPA, when con- 
sidered in relation to systemic pulsation, enables discrimination.

Our study has several limitations. One potential drawback of our investigation is that we did not match controls with respect to age and gender, and therefore possibly to their blood pressure. Due to the small number of subjects, we also decided to refrain from statistical correction for group imbalances. Furthermore, we assumed that peripheral artery pulse wave signals, i.e. at the fingertip, and intraocular pulsation are comparable in all subjects. However, both the pulse wave itself and the vessel compliance may be different within one specific subject and between individuals, or between healthy (younger) volunteers and (elderly) eye patients. Furthermore, the impact of the methodological difference between OPA measurement and assessment of peripheral blood pressure using the Finapres technology on the study results is not known.
Our data confirm the vascular character of the OPA, a parameter coming from the arterial pressure wave in the choroid. The eye modifies the incoming arterial pulse wave differently when glaucoma is present than when it is not.

Our study design is advantageous in the early investigation of a new diagnostic test [15]. However, in order to explore its clinical usefulness, more upstream evaluations involving patients with suspected glaucoma are required.

\section{Acknowledgments}

We are indebted to Hartmut Kanngiesser, PhD of Ziemer Ophthalmic Systems AG, Port, Switzerland, for the construction of the synchronization of the tonometer and the cardiovascular monitor.

We also thank Dr. Michel Calame from the Institute of Applied Physics, University of Basel, Basel, Switzerland, for the computing of the raw data.

\section{References}

1 Kanngiesser HE, Kniestedt C, Robert YC: Dynamic contour tonometry: presentation of a new tonometer. J Glaucoma 2005; 14 : 344-350.

2 Kaufmann C, Fierz A, Kollias SS, Robert YC: Ocular pulse amplitude in a case of innominate steal syndrome. Am J Ophthalmol 2002; 133:155-156.

3 Kaufmann C, Bachmann LM, Robert YC, Thiel MA: Ocular pulse amplitude in healthy subjects as measured by dynamic contour tonometry. Arch Ophthalmol 2006;124:11041108.

4 von Schulthess SR, Kaufmann C, Bachmann LM, Yanar A, Thiel MA: Ocular pulse amplitude after trabeculectomy. Graefes Arch Clin Exp Ophthalmol 2006;244:46-51.
5 Bogert LW, Lieshout JJ: Non-invasive pulsatile arterial pressure and stroke volume changes from the human finger. Exp Physiol 2005;90:437-446.

6 European Glaucoma Society: Terminology and guidelines for glaucoma, 3rd edition. www.eugs.org.

7 Goldmann H: Physiopathology of glaucoma (in German). Klin Monatsbl Augenheilkd 1973;162:427-436.

8 Stein EM, Shakarchi R: Fourier Analysis: An Introduction. Princeton, Princeton University Press, 2003, pp 29-55.

9 Hanley JA, McNeil BJ: The meaning and use of the area under a receiver operating characteristic (ROC) curve. Radiology 1982;143: 29-36.

10 Rutjes AW, Reitsma JB, Vandenbroucke JP, Glas AS, Bossuyt PM: Case-control and twogate designs in diagnostic accuracy studies. Clin Chem 2005;51:1335-1341.
11 Tan JC, Franks WA, Hitchings RA: Interpreting glaucoma progression by white-onwhite perimetry. Graefes Arch Clin Exp Ophthalmol 2002;240:585-592.

12 Minckler DS, Spaeth GL: Optic nerve damage in glaucoma. Surv Ophthalmol 1981;26: $128-148$.

13 James CB, Smith SE: Pulsatile ocular blood flow in patients with low tension glaucoma. Br J Ophthalmol 1991;75:466-470.

14 Stalmans I, Harris A, Vanbellinghen V, Zeyen T, Siesky B: Ocular pulse amplitude in normal tension and primary open angle glaucoma. J Glaucoma 2008;17:403-407.

15 Swets JA: Measuring the accuracy of diagnostic systems. Science 1988;240:12851293. Review. 